\title{
Polygenic susceptibility to testicular cancer: implications for personalised health care
}

Kevin Litchfield, Jonathan S Mitchell, Janet Shipley, Robert Huddart, Ewa Rajpert-De Meyts, Niels E Skakkebæk, Richard S Houlston and Clare Turnbull

Correction to: British Journal of Cancer (2015) 113, 1512-1518. doi:10.1038/bjc.2015.334; published online 13 October 2015

Updated online 26 May 2016: This article was originally published under a CC BY-NC-SA 4.0 license, but has now been made available under a CC BY 4.0 license. The PDF and HTML versions of the paper have been modified accordingly. (c) (i) This work is licensed under the Creative Commons Attribution 4.0 International License. To view a copy of this license, visit http://creativecommons.org/licenses/by/4.0/ 